\title{
Research of Mining Depth Influence on Floor Coupled Stree-seepage Characteristics
}

\author{
YIN Liming ${ }^{1}$ SHI Nan ${ }^{2}$ CHEN Juntao ${ }^{1}$ \\ ${ }^{1}$ State Key Laboratory of Mine Disaster Prevention and Control, Shandong \\ University of Science and Technology, Qingdao, Shandong 266590, China \\ ${ }^{2}$ Personnel Division, Shandong University of Science and Technology, Qingdao, \\ Shandong 266590, China
}

\begin{abstract}
In order to obtain the influence law of mining depth on floor coupled stress-seepage characteristics, the coupled stress-seepage characteristics were studied by numerical simululation. The results showed that when the mining depth increases, the floor failure range progressively increase with expansion of confined water guide rise. As the guilde rise of confined water, the permeation velocity became slower. Finally, through the comparative analysis of floor failure process at $800 \mathrm{~m}$ and $1000 \mathrm{~m}$ mining depths, the reasonable width of fault waterproof pillar was determined. it was safe to reserve $30 \mathrm{~m}$ and $40 \mathrm{~m}$ fault waterproof pillar respectively at $800 \mathrm{~m}$ and $1000 \mathrm{~m}$ mining depth.
\end{abstract}

Keywords: mining depth; plastic area; coupled fluid-solid; fault

\section{Introduction}

Coal is the basic energy in China, accounting for $70 \%$ natural energy, and there is about 2950 billion tons coal occurred at least $1000 \mathrm{~m}$ of mining depth which is about $53 \%$ coal total resource ${ }^{[1]}$. As the mining depth increased, the water pressure of aquifer was increasely great, and the invasion range and height of confined water in aquifuge also increased, which aggravated the potential threat to coal safety production. Field measurements indicated that more than $80 \%$ floor water inrush was due to fault structure. So far, some scholars have studied and gained plentiful research achievements of stress distribution and failure law of floor rock mass by the method of similar material simulation, theoretical analysis, numerical calculation and field measurement ${ }^{[2-7]}$. However, the research of floor coupled stress-seepage characteristics with fault was less. The floor failure feature with fault was studied by FLAC $^{3 \mathrm{D}}$, revealing the floor coupled stree-seepage characteristics at different mining depths, which provided the theoretical guidance for coal safety production above high confined water of deep mining.

\section{Fluid-solid coupling model}

The original ground stress changed induced by mining, resulting in the occurance and migration change of underground water, which influenced the underground seepage field distribution; the seepage field had certain effect of stress state of coal and rock mass by hydrostatic and hydrodynamic pressure, and permetion. Then, the failure of coal and rock mass in turn influenced the seepage characteristics of underground water. Therefore, before studying the floor failure characteristics under coupled stress-seepage, some basic hypotheses were put forward according to floor rock mass and fluid-solid coupling model of confined water was established ${ }^{[8-13]}$. There were four basie hypotheses as follows. 
(1)The matrix rock mass could be simplified to elastic medium with isotropy and continuity, whose stress and strain obeyed to generalized hook's law.

$\sigma_{\mathrm{ij}}=\lambda \delta_{i j} e+2 \mu \varepsilon_{i j}$

In the formula, $\sigma_{\mathrm{ij}}$ stands for total stress tensor; $\delta_{i j}$ is kronecker's sign; $\lambda, \quad \mu$ represents lame constants; $\varepsilon_{i j}$ is total strain; $e$ stands for volumetric strain.

(2)The surrounding rock was saturated and the water was compressible fluid.

(3)The permeability coefficient $k$ of rock mass was not a constant, which is related to plastic area. The permeability coefficient in plastic area was bigger than that of the other area. In a micro-segment pressure gradient, seepage obeyed to darcy ' s law, that is:

$q=k \frac{\partial p}{\partial x}$

In the formula, $q$ is flow; $k$ stands for permeability coefficient; $p$ represents water pressure.

(4) The effective stress of surrounding deformation obeyed to Biot's law, that is:

$\sigma_{i j}=\overline{\sigma_{i j}}+\alpha p \delta_{i j}$

In the formula, $\alpha$ stands for Biot's coefficient; $\overline{\sigma_{i j}}$ is effective stress tensor; $\sigma_{i j}$ is total stress tensor; $\delta_{i j}$ represents kronecker's sign.

Based on the basic hypotheses above, the fluid-solid coupling model of confined water was established. seepage formula

$k_{x} \frac{\partial^{2} p}{\partial^{2} x}+k_{y} \frac{\partial^{2} p}{\partial^{2} y}+k_{z} \frac{\partial^{2} p}{\partial^{2} z}=S \frac{\partial p}{\partial t}+\frac{\partial e}{\partial t}+W$ balance equation

$$
(\lambda+\mu) \mathrm{U}_{j, j i}+\mu U_{i, i j}+F_{i}+(\alpha p)_{, i}=0
$$

In the formula, $S$ represents for water storage coefficient ; $W$ is source and sink ; $e$ is volumetric deformation; $p$ is water pressure ; $\alpha$ stands for Biot's coefficient.

Stress boundary condition: $\sigma_{D}=\sigma_{0}$; displacement boundary condition: $\delta_{D}=\delta_{0} ;$ constant water head: $h_{D}=h_{0} ;$ constant flow condition: $\frac{\partial h}{\partial n}=g$.

\section{Numercial model establishment}

Based on some data of fluid-solid coupling material at home and abroad $^{[14-15]}$, the numercal model was established shown in Fig. 1. The simulation range was $180 \mathrm{~m}$ long( $\mathrm{X}$ axis), $300 \mathrm{~m}$ wide( $\mathrm{Y}$ axis) and $90 \mathrm{~m}$ high( $\mathrm{Z}$ axis). The distance of excavated coal was $100 \mathrm{~m}$ and the fault was $3 \mathrm{~m}$ wide. The bottom of model was limestone of ordovician. There was 173910 nodes and 164700 units.

The model boundary conditions were: the boundary of $\mathrm{X}$ and $\mathrm{Y}$ were constrained in its axis direction, and the bottom side was constrained along $\mathrm{Z}$ axis. The weight of overlying strata was loaded above the model by surface force. The floor coupled stress-seepage characteristics was simulated at $800 \mathrm{~m}$ and $1000 \mathrm{~m}$ depths. The rock parameters for numerical simulation were chosen from Tangkou coal mine in Shandong Energy Zibo Mining Group Co.,LTD, which were shown in Table1. 
Table. 1: Rock parameters for numerical simulation

\begin{tabular}{|c|c|c|c|c|c|c|c|}
\hline $\begin{array}{l}\text { rock } \\
\text { name }\end{array}$ & $\begin{array}{l}\text { rock } \\
\text { thick } \\
\text { ness } \\
/ \mathrm{m}\end{array}$ & $\begin{array}{l}\text { bulk } \\
\text { modulu } \\
\mathrm{s} \\
/ 10^{9} \mathrm{~Pa}\end{array}$ & $\begin{array}{l}\text { shear } \\
\text { modulu } \\
\mathrm{s} / 10^{9} \mathrm{~Pa}\end{array}$ & $\begin{array}{l}\text { friction } \\
\text { angle } \\
/^{\circ}\end{array}$ & $\begin{array}{l}\text { tension } \\
\text { strength } \\
/ 10^{6} \mathrm{~Pa}\end{array}$ & $\begin{array}{l}\text { bulk } \\
\text { density } \\
/ 10^{3} \mathrm{~kg} \\
/ \mathrm{m}^{3}\end{array}$ & $\begin{array}{l}\text { cohe } \\
\text { sion } \\
/ 10^{6} \\
\mathrm{~Pa}\end{array}$ \\
\hline $\begin{array}{l}\text { fine } \\
\text { sandstone }\end{array}$ & 60 & 12.4 & 10.4 & 42 & 2.9 & 2.4 & 3.1 \\
\hline siltstone & 18 & 14.3 & 12.5 & 53 & 3.8 & 2.1 & 4.5 \\
\hline $\begin{array}{l}\text { medium } \\
\text { particle } \\
\text { sandstone }\end{array}$ & 10 & 17 & 12.5 & 42 & 7.8 & 2.3 & 6.6 \\
\hline $\begin{array}{l}\text { medium } \\
\text { particle } \\
\text { sandstone }\end{array}$ & 4 & 12.5 & 8 & 46 & 4.5 & 2.5 & 4.5 \\
\hline $\begin{array}{l}\text { the above } \\
3 \text { coal }\end{array}$ & 4 & 4.2 & 2.4 & 28 & 1.0 & 1.4 & 1.8 \\
\hline siltstone & 4 & 9 & 5 & 40 & 3.0 & 2.4 & 4.0 \\
\hline $\begin{array}{l}\text { fine } \\
\text { sandstone }\end{array}$ & 14 & 10 & 8 & 48 & 5.8 & 2.6 & 5.0 \\
\hline $\begin{array}{l}\text { medium } \\
\text { particle } \\
\text { sandstone }\end{array}$ & 16 & 16 & 10 & 54 & 6.4 & 2.4 & 6.2 \\
\hline $\begin{array}{l}\text { interbedded } \\
\text { siltstone. } \\
\text { and } \\
\text { finestone }\end{array}$ & 8 & 10 & 8.5 & 48 & 3.9 & 2.5 & 4.8 \\
\hline siltstone & 12 & 14.5 & 13.2 & 45 & 3.1 & 2.7 & 2.4 \\
\hline
\end{tabular}

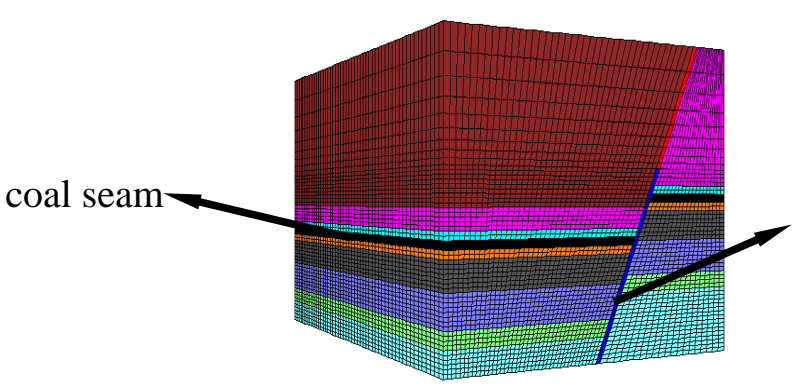

Fig. 1: Floor model with fault of deep mining

\section{Simulation result and analysis}

\subsection{Characteristics of floor coupled} stress-seepage

The floor mining failure under coupled stress-seepage was represented by plastic area. The evolution process of floor failure with $800 \mathrm{~m}$ of mining depth and $8 \mathrm{MPa}$ of water pressure was shown in Fig2, and the evolution process of floor failure with $1000 \mathrm{~m}$ of mining depth and $10 \mathrm{MPa}$ of water pressure was shown in Fig3
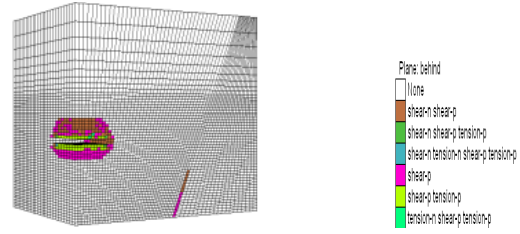

fault

advancing $72 \mathrm{~m}$

$168 \mathrm{~m}$

mining 20d

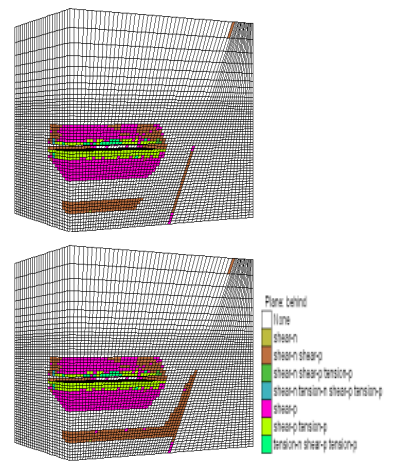

advancing $192 \mathrm{~m}$

$192 \mathrm{~m}$

mining 100d

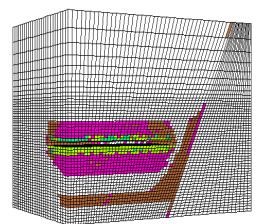

advancing

mining $35 d$

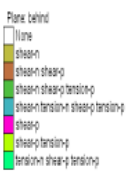

advancing

mining $365 d$

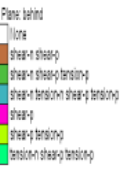




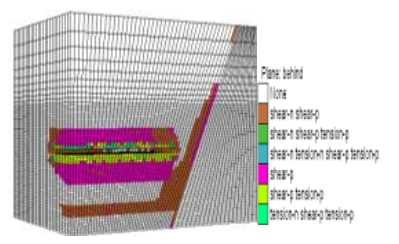

advancing $216 \mathrm{~m}$

$216 \mathrm{~m}$

mining 100d

Fig. 2. The evol

advancing with $800 \mathrm{~m}$ of mining depth and $8 \mathrm{MPa}$ of water pressure

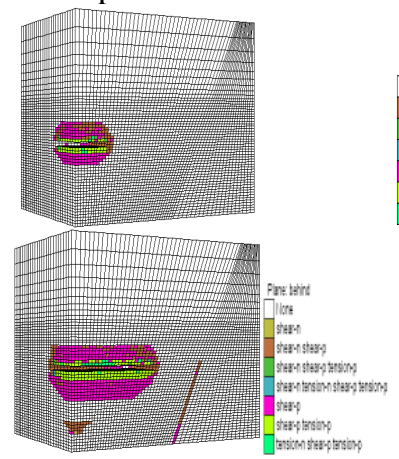

advancing $72 \mathrm{~m}$

$168 \mathrm{~m}$

mining 20d

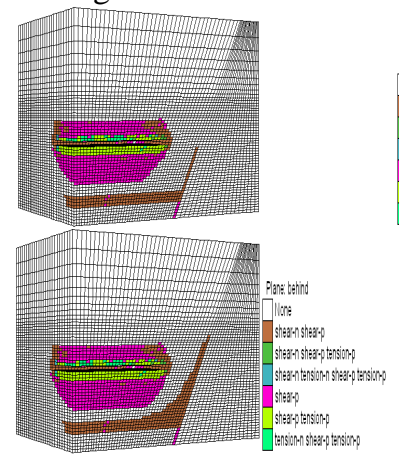

advancing $192 \mathrm{~m}$,

$192 \mathrm{~m}$

mining $100 \mathrm{~d}$

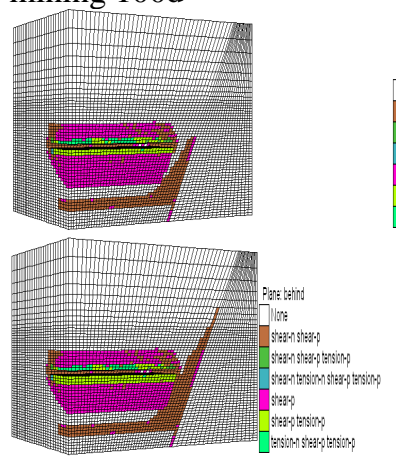

advancing $216 \mathrm{~m}$,

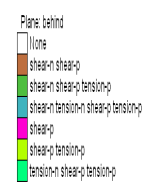

advancing

mining $35 d$

advancing

mining $365 d$

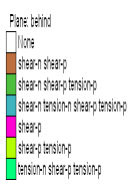

advancing
$216 \mathrm{~m}$

mining 100d mining

$365 d$

Fig. 3: The evolution process of floor failure with $1000 \mathrm{~m}$ of mining depth and $10 \mathrm{MPa}$ of water pressure

The influence law of mining depth on floor failure under coupled stress-seepage was obtained by comparison study of evolution process of floor failure in Fig2 and Fig3.

(1)The confined water had not rised when the working face was advanced $168 \mathrm{~m}$ with $800 \mathrm{~m}$ of mining depth and $8 \mathrm{MPa}$ of water pressure, however as the same advancing distance, the floor confined water appeared rise in small range with $1000 \mathrm{~m}$ of mining depth and $10 \mathrm{MPa}$ of water pressure; the range of plastic area also progressively expanded along strike direction not being connected with fault when the mining working face was $192 \mathrm{~m}$ after $100 \mathrm{~d}$ with $800 \mathrm{~m}$ of mining depth, however, the plastic failure area was connected with fault and the conductor was formed which would result in mine water inrush with $1000 \mathrm{~m}$ of mining depth above strong water pressure; the plastic failure area and guide rise height of confined water with $1000 \mathrm{~m}$ mining depth were larger than that of $800 \mathrm{~m}$ mining depth when the working face was mined 365d. These phenomenona showed that the deeper of mining depth, the bigger of floor stress, and the high stress promoted the seepage guide rise of confined water, accelerating the floor plastic failure; (2)As the mining depth increased, the coupled stress-seepage had greater effect on floor rock mass, and the floor failure depth and range also increased. The guide rise range and height of confined water were raised. However, as the guilde rise of confined water, the permeation velocity of confined water became slower;

(3)The fault water inrush of deep mining had the obvious lag characteristics. Because as the working face advancement, 
the strength of fault substance progressively decreased due to mining stress and high confinde water, and the weaken range developed upward along the fault. At last, the guide rise was higher enough to connect with the mining failure zone.

\subsection{Change law of floor water pressure}

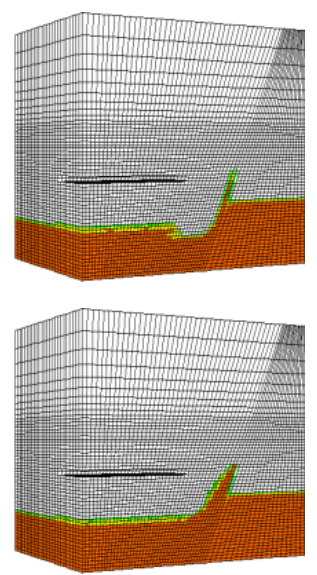

advancing 192m,

$192 \mathrm{~m}$

mining100d

$365 d$
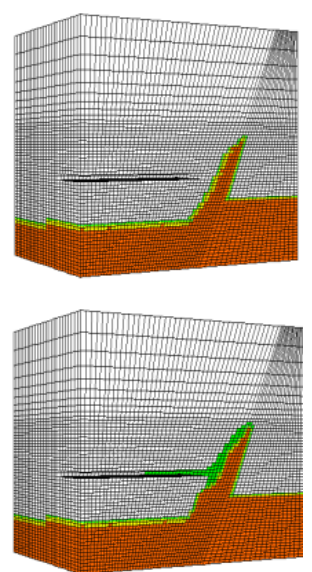

advancing $216 \mathrm{~m}$

$216 \mathrm{~m}$

mining $100 \mathrm{~d}$

$365 d$

advancing

mining

Fig. 4: Change process of water pressure with $800 \mathrm{~m}$ of mining depth and $8 \mathrm{MPa}$ of water pressure advancing

mining
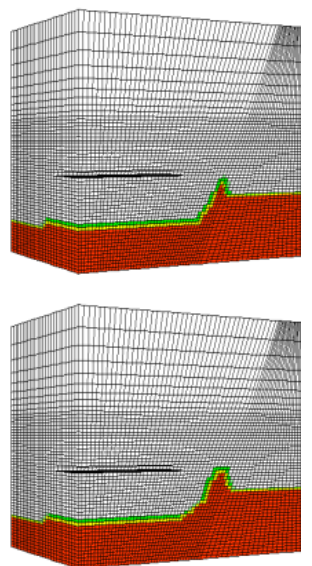

advancing $192 \mathrm{~m}$,

advancing

$192 \mathrm{~m}$

mining 100d

$365 d$

mining

advancing

advancing $216 \mathrm{~m}$

mining

$365 d$

Fig. 5: Change process of water pressure with $1000 \mathrm{~m}$ of mining depth and $10 \mathrm{MPa}$ of water pressure

The change process of floor water pressure with $800 \mathrm{~m}$ of mining depth and $8 \mathrm{MPa}$ of water pressure was shown in Fig4, and the change process of floor water pressure with $800 \mathrm{~m}$ of mining depth and $8 \mathrm{MPa}$ of water pressure was shown in Fig5.

The change law of water pressure under coupled stress-seepage condition at different depths was obtained by 
comparison study of evolution process of floor failure in Fig4 and Fig5.

(1) As the time went on, the confined water developed upward along fault due to water pressure and the water pressure changed small when the working face was mined 100d, however, the guilde rise height of confined water was up to $75 \mathrm{~m}$ next year.

(2)The guide rise velocity of water pressure along fault was initially fast and became progressively slower. At the same mining time, the deeper of mining depth, the bigger of water pressure. For example, the guilde rise range of confined water had not connected with goaf when the working face was advanced $216 \mathrm{~m}$ at $800 \mathrm{~m}$ mining depth, however, the conductor connected with goaf and guide rise range of confined water had already been formed at $1000 \mathrm{~m}$ mining depth with the same advancing distance.

\section{Fault pillar reservation}

From the simulation results above, the floor confined water was connected with mining failure zone, and the fault pillar had lose the ability to obstruct water when the fault waterproof pillar was $19 \mathrm{~m}$ of width and the working face was mined $365 \mathrm{~d}$ (the mining distance was $216 \mathrm{~m}$ ) at $800 \mathrm{~m}$ and $1000 \mathrm{~m}$ mining depth. The fault waterproof pillar was well, leaving $15 \mathrm{~m}$ intact obstructing width when the fault waterproof pillar was $31 \mathrm{~m}$ of width and the working face was mined 365d (the mining distance was $192 \mathrm{~m}$ ) at $800 \mathrm{~m}$ mining depth, as the same mining condition at 1000 mining depth, there was still $6 \mathrm{~m}$ of elastic nulcear zone between guide rise zone of confined water and minng failure zone, so the working face had the potential to water inrush. Therefore, the reasonable fault waterproof pillar above high confined water could be determined by numerical simulation, and it was safe to reserve $30 \mathrm{~m}$ and $40 \mathrm{~m}$ respectively at $800 \mathrm{~m}$ and 1000 mining depths.

\section{Conclusions}

(1)As the mining depth increased, the coupled stress-seepage had more effect on floor rock mass, and the floor failure depth and range increased. The guide rise range and height of confined water were raised. However, as the guilde rise of confined water, the permeation velocity of confined water became slower;

(2)The fault water inrush of deep mining had the obvious lag characteristics. The guide rise velocity of water pressure along fault was initially fast and became progressively slower. At the same mining time, the deeper of mining depth, the bigger of water pressure;

(3)Based on the numerical simulation results of floor faillure, the reasonable fault waterproof pillar above high confined water were determined by studying the floor coupled stress-seepage characteristics at $800 \mathrm{~m}$ and $1000 \mathrm{~m}$ mining depths, and it was safe to reserve $30 \mathrm{~m}$ and $40 \mathrm{~m}$ respectively at $800 \mathrm{~m}$ and 1000 mining depths. The simulation research provided the theoretical guidance for coal safety production above high confined water in field deep mining.

\section{References}

[1]YIN Liming, "Basic experimental study on water-inrush mechanism of floor in deep mining", Qingdao: Shandong University of Science and Technology, 2011.

[2]GUAN Yingbin, LI Haimei, and JIN Kankun, "Research of mining failure characteristics of coal floor," Safety in Coal Mines, pp. 29-32, 2003.

[3]GAO Zhaoning, and MENG Xiangrui, "Research of failure characteristics of floor deformation due to mining," Mining Safety and environmental protection, pp. 17-20, 2010. 
[4]MENG Xiangrui, XU Chenghui, and GAO Zhaoning, "Stress distribution and damage mechanism of mining floor," Journal of China Coal Society, pp. 1832-1836, 2010.

[5]LUO Liping, and PENG Suping, "Mechanism study on water-inrush hazard of floor strata in mining on confined aquifer," Journal of China Coal Society, pp. 439-462, 2005.

[6]ZHANG Liming, WANG Zaiquan, and SUN Hui, "Failure characteristics and constitutive model of rock under unloading condition," Journal of China Coal Society, pp. 1626-1630, 2009.

[7]YIN Shangxian, and WANG Shangxu, "Failure characteristics and constitutive model of rock under unloading condition," Journal of China Coal Society, pp. 264-269, 2003.

[8]JIANG Tao, "Study on constitutive model of coupled damage-permeability process of brittle rock based on micromechanics", Nanjing: Hohai University, 2006.

[9]CHEN Hongjiang, "Research on coupling theory and test of stress-damage-seepage in fractrure rock masses and its engineering application", Changsha: Central South University, 2010.

[10]ZHU Zhende, and GUO Haiqing, "Hydraulics basis of fracture rock mass", Beijing: Science Press,2007.

[11] K. Kishida, H. Taniya, and T. Adachi, "Modeling of the shear behavior of rock joints under constant normal stiffness conditions," Proceedings of the Japan symposium on rock mechanics, pp. 287-292, 2001.

[12]MA Qingyun, ZHAO Xiaodong, and SONG Zhenqi, "Break of main roof ahead of workface and ground pressure," Journal of China Coal Society, pp. 473-476, 2002.

[13]CHEN Juntao, "Basic experimental study on floor fracture and crack propagation evolution of deep mining”, Qingdao: Shandong University of Science and Technology, 2014.

[14]ZHENG Shaohe, ZHU Weishen, and WANG Shufa, "Study on the coupling problem between flow and solid of mine in confined aquifer," Chinese Journal of Rock Mechanics and Engineering, pp. 421-424, 2000.

[15]LIU Zhijun, and HU Yaoqing, "Solid-liquid coupling study on water inrush through faults in coal mining above confined aquifer," Journal of China Coal Society, pp. 1046-1050, 2007.

\section{Acknowledgements}

This work was financially supported by the National Natural Science Foundation of China ( U1361105) ,Postdoctoral Science Foundation of China (2014M551936), Postdoctoral Innovation Special Foundation of Shandong Province (201302018) and PostdoctoralApplication Research Foundation of Qingdao City. 